\title{
Biblioterapia: una propuesta terapéutica en el desgarro del tejido social
}

\section{Bibliotherapy: a therapeutic proposal in the social tear Biblioterapia: uma proposta terapêutica na dilaceração do tecido social}

\author{
Diana Paris ${ }^{1}$ ORCID: 0000-0002-1949-2194 \\ ${ }^{1}$ Espacio Integrativo Psi-Bio, directora, Uruguay, Lic. en Letras, psicoanalista, \\ diplomatura PNIE. Correo electrónico: alediparis@hotmail.com
}

\section{Resumen}

Desde una mirada holística, integrativa y psicoanalítica, entiendo que la intervención biblioterapéutica pertenece al campo de la salud mental, física, espiritual, ecológica y emocional. Se ofrece como una disciplina terapéutica enfocada en el acompañamiento de los procesos vinculados a crisis vitales, duelos, desmotivaciones y estados muy particulares del ánimo derivados de lo que en la actualidad los profesionales de la psicología mencionamos como el binomio «depresión-ansiedad covid». En este sentido, el sujeto que naufraga en el puro presente de insatisfacción, enojo y amenaza encuentra en el diálogo con el biblioterapeuta la posibilidad de cambiar el pensamiento automático mediante afrontamientos saludables. Para ello, la lectura de un texto literario puede ser el elemento desencadenante de su bionarración, y así la biblioterapia opera como poder vinculante, puente simbólico entre el sufriente y su circunstancia. En la presente comunicación - centrada en los efectos de la pandemia y la rotura de la piel social, como metáfora del aislamiento-, la biblioterapia busca promover el pensamiento crítico a partir del entrelace de modelos teóricos interdisciplinarios. Se comparte, además, una experiencia puntual —desarrollada con el formato de taller de lectura de textos ficcionales sobre La peste- y la reescritura del guion personal como vía de recuperación de espacios subjetivos bloqueados.

Palabras clave: BIBLIOTERAPIA; LITERATURA; PANDEMIA; DEPRESIÓN; BIONARRACIÓN. 


\begin{abstract}
From a holistic, integrative and psychoanalytic perspective, I understand that the library intervention belongs to the field of mental, physical, spiritual, ecological, and emotional health. It is offered as a therapeutic discipline focused on the accompaniment of the processes linked to vital crises, grief, demotivation, and very particular states of mind derived from what currently psychology professionals refer to as the binomial «depression-anxiety-covid». In this sense, the subject who is shipwrecked in the pure present of dissatisfaction, anger and threat finds in the dialogue with the librarian the possibility of changing automatic thinking through healthy confrontations. For this, the reading of a literary text can be the trigger for his bionarration, and thus, bibliotherapy operates as a binding power, a symbolic bridge between the sufferer and his circumstance. In the present communication - focused on the effects of the pandemic and the «break» of the social skin, as a metaphor for isolation- bibliotherapy seeks to promote critical thinking from the interplay of interdisciplinary theoretical models. In addition, a specific experience is shared, developed with the format of a workshop for reading fictional texts about «the plague», and the rewriting of the personal script as a way to recover blocked subjective spaces.
\end{abstract}

\title{
Keywords: LIBRARY THERAPY; LITERATURE; PANDEMIC;
} DEPRESSION; BIONARRATION.

\section{Resumo}

Numa perspectiva holística, integrativa e psicanalítica, entendo que a intervenção da biblioteca pertence ao campo da saúde mental, física, espiritual, ecológica e emocional. É oferecida como uma disciplina terapêutica focada no monitoramento de processos relacionados a crises vitais, luto, desmotivação e estados mentais muito particulares derivados do que os profissionais da psicologia atualmente chamam de binômio "depressão ansiedade covid". Nesse sentido, o sujeito que naufraga no puro presente da insatisfação, da raiva e da ameaça encontra no diálogo com o bibliotecário a possibilidade de mudar o pensamento automático por meio de enfrentamentos saudáveis. Para isso, a leitura de um texto literário pode ser o gatilho para sua bionarização e, assim, a biblioterapia funciona como uma força vinculante, uma ponte simbólica entre o sofredor e sua circunstância. $\mathrm{Na}$ presente comunicação "focada nos efeitos da pandemia e na ruptura da pele social, como metáfora do isolamento", a biblioterapia busca promover o pensamento crítico por meio da interação de modelos teóricos interdisciplinares. Também compartilha uma experiência específica —-desenvolvida com o formato de uma oficina de leitura de textos ficcionais sobre "La plague" e a reescrita do roteiro pessoal como forma de resgatar espaços subjetivos bloqueados.

Palavras-chave: BIBLIOTECA DE TERAPIA; LITERATURA; PANDEMIA; DEPRESSÃO; BIONARRAÇÃO.

Fecha de recibido: $31 / 05 / 2021$

Fecha de aceptado: 07/09/2021 


\section{Introducción}

¿Creerá la posteridad que hubo una época en que sin diluvio, sin incendio del cielo o de la tierra, sin guerra o cualquier otro desastre parecido, se ha despoblado no esta o aquella región, sino el globo entero, por así decirlo?

Francesco Petrarca

Humana cosa es tener compasión de los afligidos, y aunque a todos conviene sentirla, más propio es que la sientan aquellos que ya han tenido menester de consuelo contando novelas, o fábulas o parábolas o historias en los pestilentes tiempos de mortandad, universalmente funesta y digna de llanto.

Giovanni Boccaccio

En marzo de 2020 el mundo se detenía y la tan celebrada globalización se desvanecía como un castillo de arena a orillas del mar. Como ha sucedido en otras oleadas históricas, el tsunami apareció sin previo aviso. De pronto, las condiciones de vida (y de muerte) que diseñaban la rutina se transformaron de forma drástica. Todavía atravesamos un período de aislamiento y readaptaciones sociales inédito en lo que va de los últimos cien años... Pero la situación no es nueva... Y el tejido social se deteriora, se resiente de fatiga, abatimiento y falta de horizonte de expectativas.

Cada vez más, las consecuencias de tales daños se escuchan en el consultorio. Para ilustrar el abordaje desde la biblioterapia, tomaré el contexto presente, en espejo con la pandemia del siglo XIV, y me referiré a una experiencia con profesionales de la salud en interdisciplina para ilustrar una propuesta de afrontamiento biblioterapéutico y de reescritura del guion de vida.

Los grandes saltos de la historia (hallazgos, inventos, descubrimientos de mundos, pasaje a realidades de mayor avance tecnológico, superación de paradigmas viejos y alcance de mentalidades nuevas) se vieron perturbados en repetidas ocasiones 
por acontecimientos de hondo dolor, perplejidad, retroceso, incertidumbre psicológica y confusión general.

Me enfoco en la Edad Media para reflexionar sobre las consecuencias del coronavirus. Diferentes épocas y el mismo escarnio emocional: las cuarentenas, los confinamientos, la vida encerrada en guetos tras las murallas del miedo. Hoy, como ayer, la vieja danza de la muerte invita a bailar a ricos y pobres, a famosos y anónimos, a jóvenes y viejos sin distinción de clases.

En el annus terribilis de 1348 el contagio se propaga en las diversas ciudades portuarias de Europa. El escritor italiano Giovanni Boccaccio - testigo privilegiado de los horrores de la llamada «peste de la rata»— narró su experiencia en el Decamerón. Asombra releer en el proemio de la famosa obra la descripción desolada ante la muerte, que podría ser — salvando las cuestiones de estilo propias de la época- la crónica de un periódico actual en cualquier rincón del mundo asolado por el COVID-19. Vayan solo unos párrafos del Decamerón (2016) para comprender la inusitada coincidencia con los registros de hoy:

A la egregia ciudad de Florencia, nobilísima entre todas las otras ciudades de Italia, llegó la mortífera peste (...) que había comenzado antes en las partes orientales privándolas de gran cantidad de vivientes, y, continuándose sin descanso de un lugar en otro, se habia extendido miserablemente a Occidente. Y no valiendo contra ella ningún saber ni providencia humana (como la limpieza de la ciudad de muchas inmundicias ordenada por los encargados de ello y la prohibición de entrar en ella a todos los enfermos y los muchos consejos dados para conservar la salubridad) ni valiendo tampoco las humildes súplicas dirigidas a Dios (...). Y para curar tal enfermedad no parecía que valiese ni aprovechase consejo de médico o virtud de medicina alguna; así, o porque la naturaleza del mal no lo sufriese o porque la ignorancia de quienes lo medicaban (...) eran pocos los que curaban (...) Y esta pestilencia tuvo mayor fuerza porque de los que estaban enfermos de ella se abalanzaban sobre los sanos con quienes se comunicaban. Y más allá llegó el mal: que no solamente el hablar y el tratar con los enfermos daba a los sanos enfermedad o motivo de muerte común, sino también el tocar los paños o cualquier otra cosa que hubiera sido tocada o usada por aquellos enfermos (...). Digo que de tanta virulencia era la calidad de la pestilencia que no solamente pasaba del hombre al hombre, sino lo que es mucho más (e hizo visiblemente otras muchas veces): que las cosas que habían sido del hombre, no solamente lo contaminaban con la enfermedad sino que en brevísimo espacio lo mataban. De tales cosas, y de bastantes más semejantes a éstas y mayores, nacieron miedos diversos e imaginaciones en los que quedaban vivos, y casi todos se inclinaban a un remedio muy cruel como era esquivar y huir a los enfermos y a sus cosas [cursivas añadidas] (Boccaccio, 2016). 
Boccaccio —escribe su obra máxima entre 1351 y 1353, a escasos tres años de desatada y expandida la peste bubónica- oficia no solo de narrador, sino también de historiador de una mentalidad social, de una sensibilidad y de unos comportamientos que se repiten — según se aprecia- de manera cíclica en la humanidad.

El agotamiento del viejo orden feudal-eclesiástico, las guerras y hambrunas, la carrera por las conquistas de territorios, las expansivas relaciones entre Oriente y Occidente en el afán de ganancias por la ruta de la seda y las especias fueron algunos condicionamientos para que la pandemia fuese posible. La peste desembarcó junto a los codiciados productos de Oriente: en el cargamento de sus bodegas llegaban las ratas y, con ellas, las pulgas infectadas. Fue el inicio del derrumbamiento.

Boccaccio lo describe como un reportero de su época. Se suceden vertiginosas transformaciones sociales que dan inicio a un orden secular propio de un cambio de mentalidad (desarrollos tecnológicos, florecimiento de las universidades y democratización del saber con la llegada de los libros).

En el horizonte temporal, se aprecian las diferentes readaptaciones de las personas y sus nuevos comportamientos. Pero, antes de la llegada del Humanismo, la pandemia rompió el tejido social con terror, desesperanza y muerte. En efecto, el pasaje del siglo XIV al XV trajo desarrollo industrial, armas de fuego con pólvora, relojes de arena y mecánicos (había que controlar la finitud del tiempo), creciente anhelo por el conocimiento, innovaciones en la cartografía, aprecio por la investigación en la fisiología del cuerpo humano (aspecto que tanto debemos a la curiosidad artística de Leonardo da Vinci), y preparó el escenario para el advenimiento de la imprenta, es decir, los libros producidos a escala industrial.

Si el Renacimiento es hijo de este estado de cosas, ¿qué nuevo renacimiento sigue a los primeros años del siglo XXI, que estamos atravesando?; ¿qué nuevo orden se gestará en estos tiempos de distanciamiento social y relaciones virtuales (hasta el agobio)?; ¿de qué despojos, de cuáles hilachas emergerán los nuevos modos de comunicación y acompañamiento terapéutico en el dolor, la inclusión de los más vulnerables y la salud integral de la población? 


\section{Leer es un espacio de encuentro; (¿y en pandemia?)}

El contagio es co-tangencia.

Jacme D'Agramont

Así como el transporte por los mares fue el vehículo de la infección en la Edad Media, hoy la velocidad de los aviones es la que multiplica la expansión; como sea, el virus ya está entre nosotros y no se detiene. El virus siempre ha sido un viajero, migra, conquista, invade. Es un explorador por excelencia de nuevos territorios (humanos) que busca el contacto para sobrevivir. Tanto el virus como los humanos, todos sobrevivimos gracias al contacto, al encuentro. Somos seres sociales.

Antes hubo aldeas fantasma, huidas de los campos empobrecidos y abandono de los pequeños burgos. Hoy abundan los no lugares, igual de ociosos: desde grandes superficies comerciales hasta escuelas y universidades; aeropuertos, oficinas, museos, teatros y espacios de esparcimiento. Fantasmagorías de la modernidad. El mundo cabe en una pantalla. Estamos conectados al vacío sin co-tangencia.

Como hace ocho siglos, entre los modos de comunicación y asistencia a quienes padecen dolor y la mirada desconfiada de los otros, parece no haber ocurrido ninguna evolución... El miedo paraliza y recorta la posibilidad de contacto de unos con otros: todos somos sospechados de portar el virus. Se crea un contexto de espanto psíquico que aumenta el individualismo, mella la capacidad de resignificar el presente y proyectarse al futuro; precipita la ansiedad, ahonda la impotencia e indefensión, favoreciendo «la desesperanza aprendida», al decir de Martin Seligman (1975).

En el desarrollo de una sesión de biblioterapia hay encuentro, al menos, de dos sujetos. Se trata de una disciplina que cura leyendo-con-otro, de manera dirigida. Es un tipo-otro de la lectura convencional. Uno lee y otro escucha, ambos leen y conversan; juego de voces y de cercanía. Puede darse también una sesión grupal, y luego del encuentro se puede seguir leyendo sin el terapeuta, pero la biblioterapia nunca es una tarea solitaria. La lectura reclama como terapia la participación activo-afectiva, la escucha amorosa del psicoanálisis. 
Leer en sesión es pactar y construir un vínculo, un encuentro, un espacio transicional (en términos winnicottianos). La confianza, la libertad de ser y sentir, la capacidad para expresarse son las vías de facilitación que se generan (o no) según ese delicado equilibrio de estar presente con el otro sin con-fundirse con el otro. Sujetos en comunicación verbal y gestual, real y simbólica. Apego de miradas y voces. Co-tangencia. Paciente y terapeuta, ambos lectores de un mismo texto de infinitas construcciones significativas.

El encuadre de una sesión biblioterapéutica reclama la ingenuidad (la inocencia prevista ante lo nuevo), la actitud de estar abiertos a lo que aparezca (miedo, recuerdos encubiertos, rechazo, incomodidad), aceptando la incertidumbre y también propiciando la neuroplasticidad de las posibles y personales interpretaciones (Deberti, 2009).

En la sesión de biblioterapia el deseo circula y el relato ficcional hace posible el anclaje de la metáfora. El texto literario reinstala aquello faltante (causa de angustia, depresión, ansiedad), moviliza, transforma, y el proceso de simbolización acompañado por el terapeuta completa la tarea: el paciente in progress, en constante reconstrucción de su subjetividad.

\section{La piel de los textos}

Aceptar esos dolores atroces, enemigos de nuestra frágil envoltura que circundan a las pasiones.

Honoré De Balzac

Más vulnerables en lo emocional, con una conciencia ampliada de encierro y falta de propósitos, con creciente depresión, los consultantes de este período covid llegan en modo stop, aguardan a que no pase nada, a que pase algo. Rendidos ante el nuevo orden. Se trabaja desde el esquema provisorio, dinámico, incierto que plantea este presente de inestabilidad.

Cuarentenas. Aislamiento. Encierro. Soledad. Desapego impuesto que actualiza otros desgarros arcaicos: abandono, intemperie, angustia, ansiedad, trastornos alimenticios y del sueño, afecciones gástricas y dolencias musculares, por citar solo algunos fenómenos que se reiteran en las consultas. ¿Qué hacer? 
La respuesta siempre es multifactorial. La interdisciplina del enfoque PNIE (Psicoterapia Integrativa Psiconeuroinmunoendócrina) tiene mucho para ofrecer. Desde mi tarea profesional, en el ámbito de la salud físico-mental-emocional como terapeuta especializada en biblioterapia, si algo novedoso se ha venido a sumar ahora en mi práctica, en medio de la pandemia actual, es la posibilidad de reflexionar sobre los avances tecnológicos (un modo de nombrar las adaptaciones que realizamos) que se implementan en situaciones extremas para reparar los daños del tejido social/personal, en los que la piel oficia de muro, valla de contención y superficie de estragos. Vitiligo, alopecia, dermatitis atópica, lupus, alergias y rosácea son algunos de los idiomas de la piel que hablan los pacientes. Son lenguajes biológicos que traducen la falta de seguridad y la angustia por distanciamiento.

Me apoyo en los modelos provenientes de psicoanalistas de diferente orientación para los conceptos de «Yo-piel» (Anzieu, 1987) y «segunda piel» (Bick, 1970), así como en los aportes de John Bowlby (1986) y su teoría del apego.

La piel - manto, envoltura que deviene vestimenta, órgano frontera- se ve fragmentada, herida de falta de contacto, de ausencia, de desprotección. Me refiero a la piel simbólica, además de la biológica, que se expresa en la autoconservación amenazada. La consulta nos coloca muchas veces frente a la piel-blindaje, la defensa desesperada — tal vez el punto ciego, caja negra donde guardamos las cicatrices más remotas-, un yo fragmentado, una envoltura sin cohesionar sus partes.

La investigadora polaca Esteza Lifsza Wander — conocida como Esther Bick- se dedicó a la observación sistemática de los lactantes para elaborar sus teorías. $\mathrm{Su}$ método se focalizó en las emociones del observador como recurso para entrar en contacto con el inconsciente del bebé. Se especializó en psicoanálisis infantil, y a su tarea de investigación le debemos conceptos clave como «piel psíquica»y «segunda piel o coraza». Según Bick (1970), la sensación de la propia piel, tanto desde el interior como desde su calidad de límite a través de la piel de la madre, le permite al bebé la experiencia de la integridad de su persona. Se siente amado, reconocido, contenido. Cuando esto fracasa, surge la primera herida de amor y se forma — como defensa- una segunda piel de blindajes musculares. Como 
antenas, los sentidos nos colocan en contacto con el mundo, y de esa forma aprehendemos la realidad y la evaluamos, interpretamos, determinamos según nuestra lectura de «lo real». Esas huellas serán las que se recojan en el raíl automático, ante traumas que en la vida adulta sean tamizados por aquellas primeras experiencias.

Desde esta postura, Didier Anzieu, en 1974 —en su práctica profesional en un servicio de dermatología especializado en enfermos eczematosos-, aporta el concepto que nos ocupa, el binomio psiquis-cuerpo, el yo-piel. Ese período del desarrollo en el que el yo psíquico se diferencia del yo corporal. Esa interfaz entre el mundo interno y el mundo exterior, entre madre-niño, nexo en la relación entre el continente y el contenido. El yo-piel se desarrolla y enriquece por la integración en las diversas envolturas del sistema sensoriomotor, representado en el imaginario como una única piel-envoltura (Anzieu, 1987).

La separación opera en un proceso gradual y progresivo, pero si falla se producen anomalías que se resignificarán más tarde, cuando se viva una amenaza de pérdida de protección, y actualizarán la herida. Así, según de qué manera madre-hijo se separen, en la vertiente narcisista se manifestará la piel-escudo (falsa e impostada autonomía, seguridad propia), y en la tonalidad masoquista se representará como piel desollada (personalidad sacrificada, de víctima, que teme al abandono) (Ulnik, 2013).

Por su parte, sabemos con Bowlby (1986) que las fallas de los vínculos primarios arrojan secuelas en la adultez cuando emergen situaciones de crisis. Recordemos que el psicoanalista británico nos planteó cómo el apego es una necesidad humana arraigada en los cuidados del bebé y cómo ese lenguaje corporal que atiende sus demandas construye su confianza básica y favorece la regulación emocional. De adultos, ante instancias desestabilizadoras, las representaciones mentales de los apegos primarios reaparecen en escena, ya como vínculos afectivos estrechos que se manifiestan en conductas de proximidad, ya como alejamiento, ya como desesperada búsqueda de contacto con el cuidador. Según hayan sido las experiencias, clasificamos los modelos de apego del infante en seguro, ansioso evitativo, ansioso resistente, desorganizado-desorientado. 
Tanto el contacto elusivo como el apego por proximidad son dos temas fundamentales para tener en cuenta en situaciones de confinamiento y sus trastornos asociados. Eso puede afectar en distintos niveles, desde una tendencia a buscar a alguien amado hasta el grado patológico cuando un proceso de separación/pérdida se vive con tonalidad de rechazo o desprecio. Incluso a veces aparece el desapego como elección para anticiparse a la amenaza de sufrir por una distancia exagerada (cuando la personalidad se torna gélida, insensible como estrategia evitativa).

Considerada en apretada síntesis, con esta base teórica —en la que la piel se constituye en el órgano erógeno que aporta identidad, protección, continencia, sostén, historia personal del guion de vida, y que al vulnerarse deja al sujeto como un manojo de hilachas-, sugiero una analogía entre los dos períodos históricos que me propongo poner en espejo: el siglo XIV y el presente. Para ello, oriento el eje de reflexión a las fallas tempranas del apego y sus consecuencias (desamparo, indefensión) o del apego excesivo (fusión indiferenciada, fuente de conflicto cuando falta el otro) para trazar el paralelismo que los episodios históricos nos ofrecen: la piel y la segunda piel, la ropa. Este dispositivo (la tela, los harapos, las fibras) explica la transformación de la materia que — tras la muerte generalizada en la pandemia medieval- preparó la llegada de los libros.

\section{De los artefactos textiles a los textos}

Ni Monsieur Lavrille, sabio de la zoología, ni Planchette, célebre profesor de la mecánica, ni Japhet, maestro de química, pueden explicar de qué está hecha la piel.

Honoré De Balzac

Me gustaría proponer una hipótesis de trabajo en torno al apego/desapego que se expresa como una pregunta: ¿qué salto cultural dejará este período de crisis sanitaria en la subjetividad? El punto de partida es el interjuego entre textil-textual, en tanto ropa (piel artificial o segunda piel, frontera de apego, vínculos negados o suspendidos en pandemia), y el desarrollo de los medios 
técnicos de lectura (de la oralidad a la imprenta en el siglo XV, y las textualidades virtuales del siglo XXI).

La historiografía nos ilustra sobre el desarrollo de nuevos medios técnicos ante los hechos ocurridos a partir de la llegada de la peste negra: miles de muertos, entre los que también se encontraban los monjes amanuenses, que copiaban los libros a pedido de la nobleza y los clérigos — casi los únicos lectores del momento-, y la invención de un dispositivo que prologó el nacimiento de la imprenta. Nada habría hecho Johannes Gutenberg sin la existencia del papel. Si bien desde antes del siglo II antes de Cristo se producía en China con fibras de lino, algodón o bambú, la pandemia y los tiempos que sucedieron a la gran devastación de la peste de 1348 posibilitaron la preparación de un tipo de superficie para la letra impresa llamada «papel de trapo».

Según diversas investigaciones, la pandemia medieval dejó montañas de cuerpos, por un lado, y montañas de ropa en desuso, por otro. Tales restos serían el motor que pondría en marcha el gran invento de la imprenta. La democratización de la lectura en el imaginario colectivo está —de manera inconsciente- asociada a la reformulación de la muerte. La actividad industrial de la imprenta es así un subproducto de los desmanes causados por la peste del siglo XIV.

Paradojas de la historia: a la carencia de manos de trabajo siguieron varios desarrollos técnicos. Existen muchas variables para afirmar esto, pero sin duda una de ellas fue que las prendas que se amontonaban inútiles luego de las muertes se reciclaron, y de esa tela se creó un tipo de papel conocido desde entonces como papel de trapo. El excedente fue tal (dada la cantidad de ropa que nadie tocaba por terror a todo aquello que había estado en contacto con la enfermedad -el testimonio del Decamerón es una prueba-) que se generó sobrante de papel fabricado a partir del reciclado de la segunda piel, las telas de las vestimentas abandonadas.

El proceso incluía varios pasos: lavar, hervir, macerar (se dejaba pudrir), blanquear, eliminar tintas y colorantes, batear (se golpeaban las telas con mazos de madera), deshilachar. El material desfibrado se mezclaba con agua hasta obtener una pasta que se transformaba en una pulpa suave, que luego se esparcía sobre una plancha para secarse bajo presión. La producción de los libros 
empezaba su etapa de para todos (o casi), y su nacimiento estuvo basado en la capacidad de transformar la ropa desechada.

Hoy la piel duele por distancia, se cristaliza, se aísla, ya no huele ni tiene textura; la pantalla se roba todas esas informaciones. La falta del otro rasga la piel de las personas como un papel de trapo viejo. Nos cuidamos negando la co-tangencia. ¿Cuánto es suficientemente a distancia para evitar los contagios y cuánto es suficientemente cerca para no vaciarnos de vínculos?

Propongo la lectura en sesión biblioterapéutica como un lenguaje posible para reciclarnos del efecto de la muerte. Ataviados a la moda, con otros trapos que anulan la expresión en los rostros (tapados por mascarillas), sin la posibilidad del apego corporal (cercanía, abrazos, manos estrechadas), aceptamos la escasa sociabilidad y nos reorganizamos de un modo distinto mientras sacrificamos los encuentros verdaderos en pos de la salud. Todo un sistema de creencias puesto en jaque. Borrada la posibilidad de globalización, hemos retrocedido a la aldea pequeña de nuestra ciudad, nuestra casa, nuestro cuarto, nuestro dispositivo para conectarnos a Zoom. Cada día contamos camas disponibles para los infectados... Contamos números y estadísticas, cantidad de vacunas en el mercado y porcentajes de letalidad. El miedo nos pone a contar chances de salvación, y en esa matemática absurda ya no contamos historias.

Es verdad que la lectura de un texto literario no cura los síntomas de los que hablan en el consultorio los dolientes de ausencia y distancia, pero sí es cierto que la literatura contribuye a reacomodar las emociones que los provocan, abre el horizonte de expectativa y genera nuevas respuestas para los problemas conocidos.

Desde la PNIE y el psicoanálisis, la biblioterapia acerca su aporte. Cuando recibimos (o atendemos online) a un sujeto deprimido en su sistema inmunológico, producto de las carencias afectivas y de la imposibilidad de cercanía amorosa con su entorno, sabemos que las condiciones del covid funcionan como los disparadores desencadenantes de traumas ya programados, guardados sin gestionar, reprimidos sin poder ver la luz de la conciencia. En tal escenario, la fuerza emotiva de la literatura abre el abanico de la evocación, permite revisitar las escenas traumáticas, ofrece otro repertorio de experiencias y 
facilita la resignificación de los estremecimientos que nos tatuaron la piel con sus emociones primarias.

\section{Biblioterapia en acción}

Los científicos dicen que estamos hechos de átomos, pero a mí un pajarito me contó que estamos hechos de historias.

Eduardo Galeano

En el contexto de la consulta, la terapia encuentra en el arte un elemento de cohesión, potente ayer como hoy; el arte ha sido siempre fuente de belleza y portador de una verdad-otra sobre la realidad. En este sentido, entiendo al libro como el artefacto capaz de transformar la lectura sobre el acontecer, los vínculos, la salud, el sentimiento de abandono del sufriente, la falta de recursos básicos para vivir con dignidad.

En medio de esta pantalla macro del presente, ¿qué viene a aportar la lectura de un poema, un cuento, una novela?; ¿qué otro remedio puede aliviar tanto sufrimiento, más allá de ungüentos rústicos en el Medioevo o vacunas sofisticadas de (aún) improbable eficacia en la actualidad? Volvemos a escuchar a Petrarca (2020) como si fuera un contemporáneo: «¡Dónde estáis amigos queridos! / ¡dónde los rostros amados! / Éramos una multitud, ahora estamos casi solos...».

Leer con otros es acercar la voz, la piel, el mundo creado por la co-tangencia en el dibujo de una historia. La literatura - desde siempre - es un gran remedio que trae alivio a los estragos de la muerte real y las muertes simbólicas. La lectura como paliativo emocional, como mitigante del desastre. Acerco al paciente un texto literario, hago del efecto lector la estrategia para que me cuente lo que su dolor todavía calla, porque creo que aprender a contarnos nuestra historia es —además de un ejercicio intelectual- una toma de conciencia, una expansión del yo que habilita la voz del inconsciente.

Ante la actual crisis sanitaria mundial, se impone más que nunca una visión holística y una propuesta de bio-psico-educación que contribuyan a superar la «angustia-covid», como la ha denominado Juan David Nasio (2021). 
Lo sabemos: la conectividad digital no reemplaza al abrazo. Entre la enfermedad y la recuperación de la salud está el período de la convalecencia, que desde el punto de vista etimológico remite a 'con valor', 'con fuerza'. ¿Y en medio? Tiempo de espera. Colmar la espera implica un plan de acción para ese no tiempo entre la siembra y la cosecha. La biblioterapia - también- se plantea esta opción; supone unos mecanismos extrapolables al decurso de la vida cotidiana que sintetizaré en estos tres puntos: elegir (activar la decisión y la voluntad); disponerse (preparar el ánimo en actitud de confianza); esperar (dar tiempo al tiempo, no dejarse secuestrar por la impaciencia). La biblioterapia se despliega como un tipo de copresencia, de abrazo simbólico, de ambioma compartido en las páginas de un mismo texto.

\section{Leer es un tiempo de espera y de construcción de sentido}

La angustia por el devenir, el catastrofismo sanitario, el maltrato, la privación, la frustración, el futuro incierto, la depresión en sus dos versiones (la tristeza y el enojo), el sinsentido existencial tienen un valioso antídoto en la lectura.

Leer es una forma de impasse, tiempo de espera, recorte. Frente a una tristeza con angustia, una tristeza ansiosa, impaciente y atormentada por sus propios fantasmas, la lectura insta a mirar en otra dirección, a frenar el ir y venir obsesivo por la misma huella, abre puertas a otra realidad para regresar a la propia enriquecidos de experiencias.

Uso la noción de convalecencia como tiempo de espera, de reparación, de camino hacia la salud y el bienestar integral. Recomiendo leer como prescripción favorable para la convalecencia, como política comunitaria, como paliativo para recobrar las fuerzas perdidas por enfermedad y salir del estado de postración o amenaza. Leer literatura como factor de inmunoalfabetización (Paris, 2020), de fortalecimiento de los hábitos de inmunorresistencia, como cuando nos leían cuentos si debíamos guardar cama por alguna enfermedad de infancia. Tal recuperación de la memoria emotiva desbloquea la rumiación persistente del ahora en el pensamiento operatorio, imprime mecanismos de metaforización y 
dota a lo habitual de significados simbólicos más ricos porque ofrece palabras para lo innombrable.

Leer ficción orienta la energía hacia la recuperación de nuevos estímulos para re-sentir la huella del apego que ha quedado grabada en el cuerpo, la voz, la cercanía, el relato en la memoria afectiva. Recuperar esa escena es recuperar el aliento de quien me lee, cerca, y me ofrece amparo, seguridad. Ir en busca de ese raíl es el propósito. Y si no lo hubo, si el sujeto está árido de esas impresiones de apego seguro, ¡bienvenido, biblioterapeuta!, porque serás el encargado de instalar esa memoria y resetear ese programa de abandono emocional.

Las investigaciones basadas en las neurociencias demuestran que las personas que leen literatura tienden a ser hábiles en la lectura de las emociones de los demás, fortalecen la empatía. También la medicina considera que la lectura es una actividad cognitiva beneficiosa de cara al Alzheimer y a otras enfermedades neurológicas.

\section{Una experiencia}

Escribiendo he reparado mi alma desgarrada; en la noche, escribí soles.

Boris Cyrulnik

Quiero compartir unos breves avances de la experiencia que está en pleno proceso mientras escribo esta comunicación. En agosto de 2020, cuando se publicaba en España Lecturas que curan, inicié la coordinación de un taller para profesionales de la salud y de la lectura. La convocatoria reunió a enfermeros/as, psicólogos/as, pediatras, escritores/as, bibliotecarios/as y docentes. La consigna fue reflexionar sobre el poder sanador del arte, de la literatura en particular, pero sin descartar el cine, la música, la pintura, como agentes de biblioterapia en cada uno de sus ámbitos. En los encuentros quincenales, leemos literatura poniendo en acción un encuadre terapéutico flexible, entendiendo que estamos a la vez en una metodología de taller y de metataller, es decir, de análisis de la práctica misma.

Iniciamos la tarea con el compromiso de traer leído para la primera sesión La peste, de Albert Camus (1977). Recomendé, además, otros textos que formarán el 
corpus del programa a trabajar hasta fin de año. No es un listado cerrado ni un tiempo estricto (de hecho, solo interrumpimos en el mes de diciembre y retomamos en enero); tomé las propuestas del conjunto, leímos en grupo, arribamos a conclusiones novedosas y siempre provisorias, debatimos sobre «más de lo mismo (la peste) o algo que distraiga», y trabajamos las consignas de reescritura del guion personal/familiar.

Vale aclarar que en la pequeña ciudad donde se desarrolla la actividad (Colonia Valdense, departamento de Colonia, Uruguay) se puede resistir con presencialidad, aun en el segundo semestre del año, en los meses de ascenso de los casos. El salón es amplio y somos nueve personas. Mantenemos el distanciamiento, consideramos los protocolos, cuidamos y valoramos la presencia a conciencia, como un desafío a que se puede trabajar sin pantalla mediante y, a la vez, no contagiarse. Queda claro que elegimos la co-tangencia y no las plataformas digitales.

Volvamos a la experiencia. No es original decir que leer literatura estimula partes del cerebro relacionadas con la memoria y la afectividad, y la gente lo sabe por intuición. Los medios dan cuenta del incremento de la venta de libros durante los primeros meses de la pandemia y consideran que la ficción ayuda a procesar mejor una catástrofe, como declara en marzo, en La Vanguardia, Justo Barranco (2020) a poco de iniciada la pandemia:

En Francia, tras los graves atentados de París del 13 de noviembre del 2015, se incrementó la demanda de París era una fiesta, de Ernest Hemingway [2013], en un intento de catarsis para recuperar el optimismo y no caer en la obsesión de la amenaza yihadista. El incendio de la catedral de Notre Dame, en abril del año pasado, también hizo ganar lectores para Nuestra Señora de París, de Víctor Hugo [2019].

Como resumen de lo elaborado hasta la fecha, comparto algunos de los títulos trabajados y las motivaciones que nos permitieron leer en un continuum la misma preocupación ante la situación que refleja el covid, enfocada por voces, épocas y perspectivas diversas.

Comenzamos con la lectura de La peste (1977), de Camus. En esta, como en las siguientes novelas, recogí luego una serie de frases que fungieron de disparadores para la reflexión y la catarsis del grupo, para superar las inhibiciones y confiar en 
la propia transformación de la realidad en un contexto inhabilitante. Ofrezco como ejemplo las frases de una de las obras del corpus trabajado; de Camus seleccioné:

— La estupidez insiste siempre.

- Donde no hay esperanza, debemos inventarla.

- Todas las desgracias de los hombres provienen de no hablar claro.

— ¿Qué hacer para no perder el tiempo?... Sentirlo en toda su lentitud.

- Sienten la profunda necesidad de un calor que los una, sin embargo, no se abandonan a ella por la desconfianza que aleja a los unos de los otros.

- Sé únicamente que hay en este mundo plagas y víctimas y que hay que negarse tanto como le sea a uno posible a estar con las plagas.

— El sol de la peste hacía extinguir todo color y hacía huir toda dicha.

- Las hipótesis, en la ciencia como en la vida, son siempre peligrosas.

- Lo que es natural es el microbio. Lo demás, la salud, la integridad, la pureza, si usted quiere, son un resultado de la voluntad, de una voluntad que no debe detenerse nunca.

— En el hombre hay más cosas dignas de admiración que de desprecio.

- El hábito de la desesperación es peor que la desesperación misma.

- Sí, cansa mucho ser un pestífero. Pero cansa más no serlo. Por eso hoy en día todo el mundo parece cansado, porque todos se encuentran un poco pestíferos.

Cada sentencia propicia discusiones y reelaboraciones conceptuales, abre el juego a la subjetividad y contribuye a la expresión personal.

Luego, la dinámica de escritura se orientó a la siguiente consigna: cada participante debía elegir al menos tres sentencias de la lista de citas en las cuales le resonara algo de la propia biografía y del estado presente de la realidad. En la fase posterior, los invité a que se dispusieran a reescribir el tramo del guion de vida que se buscaba resignificar (incluso hasta se podía ficcionalizar si se creía necesario, construir una realidad-otra); y, por fin, con el texto personal 
confeccionado, leerse en público, acercar la lectura al grupo (la espera del efecto lector tiene profundas resonancias), revisar las emociones que se generan y gestionar esos estados.

La experiencia grupal/personal es — como dijimos - una oportunidad de ejercicio para replicar en sus propios ámbitos profesionales. Es así una actividad bifronte: aquí y ahora para cada uno y, a la vez, una metaejercitación a replicar en sus espacios laborales.

No es este el espacio para desarrollar los alcances de la escritura terapéutica, pero baste con la mención sobre los poderosos efectos que tiene esta práctica y los valiosos aportes del psicoanalista junguiano Ira Progoff y del padre de la resiliencia, Boris Cyrulnik. Con estos faros, en mi libro Lecturas que curan, enlacé la productividad saludable de la biblioterapia con la propuesta de escritura terapéutica.

Los otros títulos que conformaron el botiquín de remedios para el alma que se están trabajando en el taller de lectura y escritura terapéutica son el Decamerón, de Giovanni Boccaccio; La peste escarlata, de Jack London (2017); Ensayo sobre la ceguera, de José Saramago (1996), y Distancia de rescate, de Samanta Schweblin.

En esas páginas, pestes de diferente calaña (ecológica, de agobio, de castigo divino) dan los pre-textos para zambullirse en los textos propios, recuperar la huella mnémica al escuchar historias ajenas que hacen sentido en el sujeto que lee -el cual se permite olvidar la obra literaria y centrase en el efecto personal que despliegan ciertas emociones dormidas-, apreciar el eco de la historia en el presente. Lo repetimos: leer nos saca del adormecimiento psíquico, del dolor, de la indiferencia; leer despierta la emoción anestesiada y alivia la fatiga acumulada de tantos interdictos sanitarios que nos acorazan como escudos que asfixian.

La propuesta es cambiar la farmacia por la biblioteca. Es leer con otros para ensanchar el criterio de verdad, para revisar la noción de patológico, para ampliar el menú de estrategias salutogénicas, para gestionar las emociones y consolar viejos dolores disfrazados de covid actual. Es leer con otros, junto con otros, para 
reflexionar sobre el valor de la existencia y para ser más humanos en contacto con la belleza, como naciendo a una nueva piel en permanente construcción.

\section{Referencias bibliográficas}

Anzieu, D. (1987). El yo-piel. Madrid: Biblioteca Nueva.

Barranco, J. (2020). Libros de epidemias y confinamiento. La Vanguardia.

Recuperado de

https://www.lavanguardia.com/cultura/20200316/474173941106/librosepidemias-la-peste-camus.html

Bick, E. (1970). La experiencia de la piel en las relaciones de objeto tempranas. International Journal of Psychoanalysis (49), 2-3.

Boccaccio, G. (2016). El Decamerón: antología. Madrid: Alianza.

Bowlby, J. (1986). Vínculos afectivos: formación, desarrollo y pérdida. Madrid: Morata.

Camus, A. (1977). La peste. Barcelona: Edhasa.

Deberti, C. (2009). Biblioterapia: propuesta de un encuadre. Revista Itinerario, 4(11). Recuperado de https://itinerario.psico.edu.uy/revista\%20anterior/Biblioterapiapropuestade unencuadre.htm

London, J. (2017). La peste escarlata. Barcelona: Libros del Zorro Rojo.

Nasio, J. (2021, enero 21). [Entrevista de M. Avignolo]. Depresión Covid. Clarín. Recuperado de https://www.clarin.com/sociedad/depresion-covid-ineditapandemia-afectara-largo-plazo_0 JBqTAwxXW.html

Paris, D. (2020). Lecturas que curan: beber dos cubos de agua con estrellas y otras técnicas de biblioterapia. Barcelona: Del Nuevo Extremo.

Petrarca, F. (2020). Cancionero. Madrid: Verbum.

Saramago, J. (1996). Ensayo sobre la ceguera. Madrid: Alfaguara.

Seligman, M. (1975). Helplessness: On Depression, Development, and Death. San Francisco: W. H. Freeman.

Ulnik, J. (2013). La piel de zapa de Balzac y el problema del deseo en los pacientes dermatológicos. En Unidad de Docencia y Psicoterapia (Ed.), 
1500 Seminarios, Mente y literatura: Vol. 10. Granada. Recuperado de https://docplayer.es/14358198-La-piel-de-zapa-de-balzac-y-el-problemadel-deseo-en-los-pacientes-dermatologicos-autor-prof-dr-jorge-c-ulnik-11.html

\section{Notas del editor}

El presente manuscrito fue aprobado para su publicación por Cristina Deberti.

La corrección de estilo del presente texto fue realizada por Irene Busakre en el marco del convenio celebrado entre la FHCE (Tecnicatura Universitaria en Corrección de Estilo-Facultad de Humanidades y Ciencias de la Educación) y la FIC (Facultad de Información y Comunicación).

\section{Nota de contribución autoral}

El presente manuscrito fue elaborado $100 \%$ por el autor. 